\title{
Long-term dietary compensation for added sugar: effects of supplementary sucrose drinks over a 4-week period
}

\author{
Marie Reid ${ }^{1,2}$, Richard Hammersley ${ }^{3}$, Andrew J. Hill ${ }^{4}$ and Paula Skidmore ${ }^{5}$ \\ ${ }^{1}$ Psychology Department, Queen Margaret University College, Edinburgh, UK \\ ${ }^{2}$ Feeding and Eating Disorder Service, Great Ormond Street Hospital, London, UK \\ ${ }^{3}$ School of Life Sciences, Glasgow Caledonian University, Glasgow, UK \\ ${ }^{4}$ Academic Unit of Psychiatry and Behavioural Sciences, School of Medicine, University of Leeds, UK \\ ${ }^{5}$ School of Medicine, Health Policy and Practice, University of East Anglia, Norwich, UK
}

(Received 1 February 2006 - Revised 11 July 2006 - Accepted 18 September 2006)

\begin{abstract}
The long-term physiological effects of refined carbohydrates on appetite and mood remain unclear. Reported effects when subjects are not blind may be due to expectations and have rarely been studied for more than $24 \mathrm{~h}$. The present study compared the effects of supplementary soft drinks added to the diet over 4 weeks on dietary intake, mood and BMI in normal-weight women $(n$ 133). Subjects were categorised as 'watchers' or 'non-watchers' of what they ate then received sucrose or artificially sweetened drinks $(4 \times 250 \mathrm{ml}$ perd). Expectancies were varied by labelling drinks 'sugar' or 'diet' in a counter-balanced design. Sucrose supplements provided $1800 \mathrm{~kJ}$ perd and sweetener supplements provided $67 \mathrm{~kJ}$ perd. Food intake was measured with a $7 \mathrm{~d}$ diary and mood with ten single Likert scales. By 4 weeks, sucrose supplements significantly reduced total carbohydrate intake $(F(1,129)=53.81 ; P<0.001)$, fat $(F(2,250)=33.33 ; P<0.001)$ and protein intake $(F(2,250)=28.04$; $P<0 \cdot 001)$ compared with sweetener supplements. Mean daily energy intake increased by just under $1000 \mathrm{~kJ}$ compared with baseline $(t(67$ df) $=3.82 ; P<0.001)$ and was associated with a non-significant trend for those receiving sucrose to gain weight. There were no effects on appetite or mood. Neither dietary restraint status as measured by the Dutch Eating Behaviour Questionnaire nor the expectancy procedure had effects. Expectancies influenced mood only during baseline week. It is concluded that sucrose satiates, rather than stimulates, appetite or negative mood in normal-weight subjects.
\end{abstract}

Sucrose: Artificial sweeteners: Fat intake: Energy intake: Body weight

Obesity has become a major public health problem in many countries including the UK. For example, in 2002 in England, where the present sample was recruited, $43 \%$ of men and $34 \%$ of women were overweight and $22 \%$ of men and $23 \%$ of women were obese (BMI $>30 \mathrm{~kg} / \mathrm{m}^{2}$ ) (Department of Health, 2002). Obesity is due to a long-term energy surplus, with more energy taken in than expended (Skidmore \& Yarnell, 2004). In theory, the solution to obesity is increasing expenditure and decreasing intake but this simplistic strategy is rather ineffective for many individuals (Skidmore \& Yarnell, 2004). Paradoxically, over the past 40 years a steady decrease in reported average total energy intake has been found, from over $10460 \mathrm{~kJ}(2500 \mathrm{kcal}) / \mathrm{d}$ in the $1950 \mathrm{~s}$ to under $8370 \mathrm{~kJ}(2000 \mathrm{kcal}) / \mathrm{d}$ in the 1990s (Ministry of Agriculture, Fisheries \& Food, 1991). This implies either underreporting (Goris et al. 2001) or energy expenditure decreasing even faster than intake (Prentice \& Jebb, 1995; Astrup, 2005). One factor in the surplus is a high-fat diet (Hill et al. 2000). Although this is not the sole causal factor, reducing dietary fat intake is an important means of reducing energy intake and appears to be crucial in the prevention of obesity (Astrup et al. 2000; Astrup, 2005).
Fat is energy-dense, but less satiating than carbohydrates (Blundell \& Burley, 1990). Complex carbohydrates are recommended in low-fat diets and help promote body-weight control and reduce the risk of heart disease (British Nutrition Foundation, 1999; Astrup et al. 2000), but the role of simple carbohydrates is less certain, and there may be certain health risks (Byrnes et al. 2003; Satia et al. 2005). Claims that they trigger cravings for carbohydrate and low mood may have been overstated (Reid \& Hammersley, 2001), but still require controlled empirical investigation. Fat and sucrose intake are negatively correlated in surveys (Raben et al. 1997) but there is controversy over the effects of refined carbohydrate on appetite and weight control (Reid \& Hetherington, 1997; Saris, 2003), based primarily on studies of under $24 \mathrm{~h}$ duration. Sugars may increase or decrease appetite and satiety (Geiselman \& Novin, 1982; Hill \& Blundell, 1986; Spitzer \& Rodin, 1987; Teff et al. 1989; Blundell et al. 1994) and may or may not affect mood (for example, Lieberman et al. 1986; de Castro, 1987; Thayer, 1987; Pivonka \& Grunewald, 1990; Benton, 2002) and craving (Toornvliet et al. 1997). Not all studies have blinded participants to what they ingest (see Reid \& Hammersley, 1999), which

Abbreviations: DEBQ, Dutch Eating Behaviour Questionnaire; MAFF, Ministry of Agriculture, Fisheries and Food.

* Corresponding author: Professor Marie Reid, fax +44 131317 3605, email mreid@qmuc.ac.uk 
may help explain variations in findings as participants may be influenced by their cognitive expectations and behave according to the 'well-known rule' (Poulton, 1989), in this case that carbohydrates affect appetite and mood.

Additionally, short-term studies may provide limited information since adaptation to these sorts of dietary manipulation probably takes days rather than hours (Astrup \& Raben, 1992). Long-term work is more difficult to conduct, but is important for understanding dietary regulation and obesity. There have been only five long-term studies of the effects of refined carbohydrates in the diet of obese or overweight individuals. All have assessed the role of simple carbohydrates in low-fat weight-loss diets. Three using energy-reduced weight-loss diets found that the carbohydrate content of the diet did not influence weight loss (Surwit et al. 1997; Poppitt et al. 2002; Brinkworth et al. 2004). Two other studies (Raben et al. 1997, 2002) found a high-starch diet led to weight loss, but that individuals preferred the high-sucrose diet with which they gained weight slightly. This was probably due to palatability and thus increased energy intake from sweet drinks. Raben et al. (2002) found that sucrose supplementation increased energy intake over 10 weeks, with consequent increases in BMI. Participants were not aware of the content of the supplements but were able to guess by the end of the study.

A further two blinded trials added sugar or aspartame to the natural diet of normal-weight participants (Tordoff \& Alleva, 1990; Reid \& Hammersley, 1998). The former study found that fructose increased energy intake over 3 weeks compared with aspartame, although the effect was complicated by sex differences. No effects after the first day of intervention were reported in the second study.

Thus, three long-term studies have found that sucrose (or fructose) increases energy intake, while three have not found this effect, or have found as much weight loss as with alternative dietary regimens. A final consideration is that studies investigating the increased consumption of sugar-sweetened drinks suggest that the ingestion of sugar in liquid form does not lead to satiety as much as when it is in solid food (Goran, 2001; de Graaf et al. 2004).

To sum up, the previous literature suggests that either (a) sugar satiates, or (b) it does not satiate well, or (c) it actively stimulates appetite for carbohydrates and energy intake. Table 1 summarises the predicted outcomes of these alternative theories when sugar is added to the diet as a supplement.

The present study set out to test the alternative theories in Table 1 following on from Reid \& Hammersley (1998) which involved normal-weight individuals and a natural free-living diet with blind supplementation with sugar or aspartame over 4 weeks and independent manipulation of what participants believed they were receiving. To maximise the likelihood of adverse effects of sugar, it was given in liquid form. The sample size was calculated using the effect sizes in Reid \& Hammersley (1998). The study aim was to evaluate the effects of supplementary soft drinks added to the diet over 4 weeks under blind conditions on dietary intake, hunger, mood and BMI. It was hypothesised that sucrose supplementation would be compensated for in the diet, without weight gain or adverse effects on mood.

Two additional factors were examined simultaneously: the influence of drink labelling on behaviour and the effects of restrained eating. It was hypothesised that participants not blinded to the manipulation and those watching their weight would show poorer compensation. 'Watching what you eat' has been proposed as an activity distinct from dieting (Nichter et al. 1995), although the two are often conflated in nutritional surveys. In order to examine restraint without confounding it with dieting, two groups of women were compared; women who had low restraint scores, of normal weight and not currently dieting or 'watching what they eat' (Nichter et al. 1995) and women with high restraint scores, also of normal weight, not dieting, but 'watching what they eat'. Women who engage in this behaviour have sufficient energy intake to maintain weight, but exert deliberate control over what they eat (Reid et al. 2005b). This classification is correlated with restraint measured by the Dutch Eating Behaviour Questionnaire (DEBQ).

\section{Research design and methods}

This was a long-term study involving 1 week of baseline data collection followed by 4 weeks of sweet drink supplementation. Drinks contained either sucrose or an artificial sweetener (aspartame). Participants were either informed that they were receiving sugary drinks or 'diet' drinks, meaning that half were correctly informed about the drink content and half misinformed. In addition, participants were recruited according to whether they were or were not currently watching their weight. This resulted in a $2 \times 2 \times 2$ design (sucrose $v$. aspartame, drinks labelled sugar $v$. labelled aspartame or diet, watcher $v$. non-watcher) with 133 subjects, as shown in Table 2.

\section{Subjects}

In total, 161 women were screened and recruited, but twentyeight failed to complete all 5 weeks of the study, leaving an

Table 1. Predicted effects of sugar supplementation on diet and mood

\begin{tabular}{llcc}
\hline & \multicolumn{1}{c}{ Sugar satiates } & Sugar does not satiate well & Sugar stimulates appetite for carbohydrates \\
\hline Total energy intake & $\begin{array}{c}\text { Does not increase by value of } \\
\text { supplement } \\
\text { Reduces to compensate } \\
\begin{array}{c}\text { Farbohydrate intake elsewhere in } \\
\text { elsewhere in the diet }\end{array}\end{array}$ & $\begin{array}{c}\text { Increases by value of } \\
\text { supplement } \\
\text { Stays the same }\end{array}$ & $\begin{array}{c}\text { Increases beyond the value } \\
\text { of the supplement } \\
\text { Increases }\end{array}$ \\
$\begin{array}{l}\text { Hunger and mood } \\
\text { Reduces to compensate }\end{array}$ & Stays the same & Stays the same \\
& No changes & No changes & $\begin{array}{c}\text { Hunger increases, arousal decreases, } \\
\text { mood worsens }\end{array}$ \\
\hline
\end{tabular}


Table 2. Number of subjects in each cell of the experimental design*

\begin{tabular}{|c|c|c|c|c|c|c|c|}
\hline & \multicolumn{3}{|c|}{ Received sugar } & \multicolumn{3}{|c|}{ Received aspartame } & \multirow[b]{2}{*}{ Grand total } \\
\hline & Watchers & Non-watchers & Total & Watchers & Non-watchers & Total & \\
\hline Drink labelled 'sugar' & 20 & 13 & 33 & 20 & 12 & 32 & 65 \\
\hline Drink labelled 'diet' & 20 & 15 & 35 & 19 & 14 & 33 & 68 \\
\hline Grand total & 40 & 28 & 68 & 39 & 26 & 65 & 133 \\
\hline
\end{tabular}

*Uneven cell sizes are due to the relative rarity of women of normal weight who did not watch what they ate.

achieved sample of 133. Participants included hospital and university staff, teachers and teaching assistants from the local schools and mature university students, as well as members of the general public. Volunteers were recruited by advertising around the University and in the local community, using posters and local newspapers. Recruitment of watchers proceeded more quickly than non-watchers, so cell allocation was randomised separately for watchers and non-watchers. Initial inclusion criteria were being female, aged between 20 and 55 years old and of normal weight (BMI 18.5$24.9 \mathrm{~kg} / \mathrm{m}^{2}$ ). However, recruitment found a number of healthy women without any signs of an eating disorder, or restraint, whose BMI lay between 17 and $18.5 \mathrm{~kg} / \mathrm{m}^{2}$; six women in this BMI range were included in the study. Exclusion criteria included currently dieting or exercising to lose weight, a dislike of popular sweet carbonated drinks, being diabetic, pregnant or lactating, suffering from any serious physical or mental health problem or being on any medication that would interfere with mood such as antidepressants. Participants also had to be able to take part in the study for 5 consecutive weeks. All participants were provided with written and oral information about the study and participated after the screening interview on the basis of informed consent, which included consent to consuming test drinks that might or might not contain sugar. Subjects were paid a disturbance allowance for participating in and completing the study. Consent was obtained from the research ethics committee at the University of Essex.

\section{Procedure}

Subjects attended the laboratory seven times, for initial screening, at the start of the baseline week, the start of each of the four intervention weeks and at the very end of the last week. Potential subjects came in for an initial screening interview on a Friday when they were given a written description of the study and what the study entailed. Participants were informed that they would receive drinks that had been especially developed for the experiment but which tasted very similar to commercially available beverages such as 'Tizer' or 'Irn-Bru' which are commercial drinks in the UK that are not as well known as colas or lemonades. The purpose of the study was stated as being 'to investigate the effects of certain nutrients in soft drinks on people's psychological well being'. Participants actually received Irn-Bru, but in uniform unmarked bottles that did not reveal whether it contained sucrose or artificial sweeteners. A taste test was then administered with a rating form to screen out any subjects who did not like the drink that they were to be allocated throughout the study. Height and weight were then recorded and screening questionnaires were administered including the DEBQ (van Strien et al. 1986) and the brief 'Watchers' questionnaire devised by Reid et al. (2005b). Subjects who scored more than 40 on the DEBQ restraint scale were excluded. Participants remaining eligible were asked to return the following Monday when baseline blood samples were taken by a phlebotomist in the morning after breakfast. They were also asked to bring in a urine sample on that day. Finally, on that day subjects were given a food diary to complete in conjunction with the UK Ministry of Agriculture, Fisheries and Food (MAFF) food atlas for that week (baseline week). The experimenter spent about 30 min training each subject on the accurate completion of the diary.

A further appointment was scheduled for the following Monday in the morning (week 1 of the 4-week intervention). Their baseline diaries were collected and checked for accuracy, their body weight and bioimpedance measurements were taken as described further later. This time, participants were given 1 week's supply of twenty-eight test drinks and were instructed to drink the agreed amount each day at the specified times $(11.00,14.00,18.00$ and 20.00 hours) and to rate their mood directly after ingestion of the drink in the $7 \mathrm{~d}$ food and mood diary that they were given again. Participants were advised to keep unopened bottles in a refrigerator or a cool place. This procedure was repeated on the following three Monday or Tuesday mornings, to make up 4 weeks of intervention. Every week, participants were also asked in an open-ended way to report any unusual experiences or symptoms they had felt that might have been related to the soft drink. Finally, subjects returned at the end of intervention week 4, when their weight, bioimpedance measures and another blood sample were taken and their diaries were checked and collected.

\section{Experimental drinks}

Subjects received four $250 \mathrm{ml}$ bottles of drink per d (total $1800 \mathrm{~kJ} ; 105 \mathrm{~g}$ carbohydrate) in uniform bottles with the labelling manipulated. This quantity of supplementation was chosen on the basis of our previous work (Reid \& Hammersley, 1998) to be the minimum that was likely to have an effect on dietary intake. Larger supplements would be more likely to have an effect, but are ethically and practically problematic. The sucrose-sweetened Irn-Bru contained $180 \mathrm{~kJ} / 100 \mathrm{ml}$, $10.5 \mathrm{~g}$ carbohydrate and $0.35 \mathrm{mg} \mathrm{Fe}$ with traces of protein and fat. The diet Irn-Bru had $17 \mathrm{~kJ} / 100 \mathrm{ml}$ and $0.89 \mathrm{~g}$ carbohydrate, with the same amount of $\mathrm{Fe}$, protein and fat. IrnBru and diet Irn-Bru can be discriminated by taste and smell when both are available for comparison. However, discrimination is difficult when only one is available (Reid \& 
Hammersley, 1998). The cover story that the drink was specially prepared for the study was intended to make this even less likely. When asked about the effects of the drinks, respondents reported a number of idiosyncratic effects, such as increased libido, that were unlikely to be related to the drink content. No respondent reported suspecting that they were receiving a soft drink that was mislabelled or differed from what they had been told to expect.

\section{Questionnaires}

Following the procedure in the pilot study (Reid et al. 2005b) where the validity of 'watching what you eat' was investigated by relating it to the psychological trait of dietary restraint, participants in the present study were asked to self-complete the ten questions from the DEBQ restraint scale (van Strien et al. 1986), relating to concern for dieting, restriction of food intake and weight fluctuation. They also had to complete the following four questions using the questionnaire devised by Reid et al. (2005b), adapted from the study by Nichter et al. (1995):

(1) Would you call yourself someone who watches what they eat? Always, most of the time, sometimes, never. The scale was reverse-scored for analysis, with 'never' being 1 and 'always' 4.

(2) Would you call yourself someone who diets? This used the same scale and the same scoring method.

(3) Are you currently watching what you eat? Yes/No.

(4) Are you currently dieting? Yes/No.

Participants were then classified as 'watchers' who answered 'yes they currently watched what they ate' or 'non-watchers', who did not. This distinction may clarify the difference between 'healthy' and 'unhealthy dieting'. The rationale for this classification is described in Reid et al. (2005b).

\section{Food, mood and activity diary}

Participants also completed a $7 \mathrm{~d}$ food diary for the 5 weeks of the study. The diary was divided into $1 \mathrm{~h}$ time slots. Respondents were requested to record all food and liquid intake, the exact amount consumed, and the time of day the food was consumed. In order that participants could make a more accurate estimate of the quantities consumed they were instructed to use the MAFF food atlas and its codes in conjunction with the diaries. The MAFF atlas (Nelson et al. 1997) provides pictures of various common foods and drinks with indicative standard portion sizes that can be referred to in diaries to describe portion sizes. Diary training was given in week 1 and diary completion was monitored and discussed every time participants visited the laboratory. Participants were also informed that they could contact the experimenter if they had any questions or problems. The diary also contained visual analogue scales measuring appetite and mood daily for participants to complete before and after they had consumed each test drink at 11.00, 14.00, 18.00 and 20.00 hours. The ends of the scale were marked energetic/ tired, hungry/full, thirsty/not thirsty, happy/sad, angry/calm, anxious/composed, disgusted/satisfied, restless/relaxed, sober/ intoxicated and ill/well, measuring hunger motivation and the two mood dimensions proposed by Thayer (1978). As this was a long-term study, no attempt was made to assess any changes within $2 \mathrm{~h}$ after each drink. Participants were also asked to keep to their usual pattern of exercise. In order to check that this was the case, activity levels were recorded in the diary kept throughout the study by asking participants to note what exercise they undertook and for how long.

\section{Measurements}

Anthropometric measurements. Height was measured with a wall-mounted stadiometer and body weight with a digital scale. In addition, on each visit body composition was measured using the Bodystat ${ }^{\circledR} 1500$ bioimpedance machine (Bodystat Ltd, Isle of Man, UK). Participants were asked to lie on a bed and rested for 5 min before measurements were taken. The bioimpedance machine measured body fat, water and lean mass. It also measured BMI and BMR (in kcal). The BMR (at rest) was estimated using the Brozek and Grande formula. This formula is based on the lean weight of a subject and not on total body weight.

Urine samples. Participants were asked to bring in a urine sample every time they visited the laboratory. They were informed that urine would be analysed and would serve as an indicator of the ingestion of the beverages. This practice of collecting physical data as a 'bogus pipeline' has been shown to improve participant compliance (Roese \& Jamieson, 1993). In reality, the urine samples were discarded.

Blood samples. Blood samples were taken by a phlebotomist at baseline and the last week of the study (week 5) after breakfast and were anti-coagulated with EDTA. Total cholesterol was measured by enzymic determination according to the method of Allain et al. (1974) and non-fasting TAG was measured according to the method of Bucolo \& David (1973) in an AU 600 multiparametric biochemical analyzer (Olympus, Hamburg, Germany).

\section{Statistical analysis}

All anthropometric, lipid and dietary variables were normally distributed except for TAG which was exponentially transformed. Relationships between watchers and non-watchers were investigated using the independent $t$ test. Raw mood data were generally not normally distributed. To eliminate individual differences in scale use, the grand mean and standard deviation for all mood ratings for each subject were calculated and each mood rating was $Z$-score standardised against the subject's grand mean and standard deviation (Poulton, 1989). Differences in anthropometric, lipid and dietary measures were examined using general linear modelling with a repeated-measures design (week 0,1 or 4), with type of drink given and expectancy as fixed variables. In initial analyses, restraint status (watching or non-watching) was also included, but there were no effects of this manipulation so analyses reported in the present paper exclude this variable. Differences in moods were examined with general linear modelling using time of day and day of week as repeated measures across the baseline week, with drink and expectancy as independent factors. Where appropriate, post hoc comparisons were made with $t$ tests. All analyses were performed using SPSS version 10 for Windows (SPSS Inc., Chicago, IL, USA). Because there were multiple analyses the standard significance level was set to $P<0.001$ and all effects and differences reported are significant at this level unless otherwise noted. 


\section{Results}

Baseline results

There were no differences in baseline measures between those 133 who completed the study and the twenty-eight who did not. Most non-completers were unable to complete the diaries adequately, either because they found it difficult, or because of unanticipated life changes, such as having to travel, which disrupted their eating patterns. Of the 133 participants, seventynine participants were watchers (mildly restrained eaters) and fifty-four were not. Table 3 shows the baseline data, comparing watchers and non-watchers. Differences between watchers and non-watchers were maintained across the 4-week intervention.

\section{Effects of the experimental intervention}

Despite the baseline significant differences between watchers and non-watchers, there were no significant effects of restraint status on any of the experimental analyses. For this reason and for brevity, results are presented here without 'watching' as a factor. Results with 'watching' included did not differ materially from those presented.

\section{Energy intake}

There was a small effect of time $(F(2,128)=5 \cdot 17 ; P<0 \cdot 01)$, due to energy intake changing over the intervention period. There was also a quadratic interaction with drink $(F(1,129)=17 \cdot 83$; $P<0 \cdot 001)$, suggesting that participants receiving the sucroseand aspartame-sweetened drinks behaved differently.

Fig. 1 shows energy intake during baseline and the first and fourth weeks of the intervention. It can be seen that the expectancy manipulation had no effect. Post hoc paired $t$ tests were conducted separately for participants who received sucrose and those who received aspartame. After receiving sucrose, energy intake was higher at week 1 ( $t$ (67 df $)=6.44 ; P<0.001)$ and at week 4 than at baseline $(t$ (67 df $)=3.82 ; P<0.001)$ and week 1 and week 4 did not differ $(t(67 \mathrm{df})=1.81 ; P=0.075)$, although there was a downwards trend. The increase was approximately half the energy value of the supplementary drinks. Comparing the energy value of the supplement and the size of the change between baseline and week 4 with a paired $t$ test, in the sucrose group the increase in energy intake was significantly lower than the supplement value $(t(67 \mathrm{df})=4.84 ; P<0.001)$. After receiving aspartame, by paired $t$ tests energy intake was marginally lower at week $1(t(64 \mathrm{df})=2 \cdot 18$; $P<0.05)$ and at week $4(t(64 \mathrm{df})=2.0 ; P<0.05)$ than at baseline, and week 1 and week 4 did not differ $(t(64 \mathrm{df})=0 \cdot 16 ; \mathrm{NS})$.

\section{Nutrient intake}

In groups receiving sucrose drinks, carbohydrate intake increased approximately half the amount of the content of the supplements, while in groups receiving aspartame, carbohydrate intake remained approximately constant, so there was a main effect of drink $(F(1,129)=53.81 ; P<0 \cdot 001)$. Another way of describing these findings is that subjects receiving carbohydrate supplementation proportionately decreased their voluntary carbohydrate intake elsewhere in the diet. Additionally, across all groups, fat intake tended to decrease across the intervention period $(F(2,250)=12.68 ; P<0.001)$ and fat intake decreased more amongst groups receiving sucrose drinks $(F(2,250)=33 \cdot 33$; $P<0.001)$. This decrease applied across MUFA, PUFA and SFA. Protein intake tended also to decrease $(F(2,250)=15 \cdot 60$; $P<0.001)$ and this decrease was also greater in the group receiving sucrose $(F(2,250)=28.04 ; P<0 \cdot 001)$. Fig. 2 summarises these data, showing the proportional changes in carbohydrate, fat and protein intake. There were no significant differences in alcohol intake, cholesterol or fat intakes.

Table 3. Characteristics of participants at baseline (Mean values and standard deviations)

\begin{tabular}{|c|c|c|c|c|c|c|c|}
\hline & \multirow[b]{2}{*}{$n$} & \multicolumn{2}{|c|}{ All subjects } & \multicolumn{2}{|c|}{ Watchers } & \multicolumn{2}{|c|}{ Non-watchers } \\
\hline & & Mean & SD & Mean & SD & Mean & SD \\
\hline Age & 133 & $31 \cdot 8$ & $9 \cdot 1$ & $32 \cdot 2$ & $9 \cdot 4$ & $31 \cdot 2$ & $8 \cdot 7$ \\
\hline Height (cm) & 133 & 165 & $6 \cdot 4$ & 165 & $5 \cdot 6$ & $165^{\star *}$ & $7 \cdot 4$ \\
\hline BMI $\left(\mathrm{kg} / \mathrm{m}^{2}\right)$ & 133 & 22.5 & $2 \cdot 8$ & 23.4 & $2 \cdot 7$ & $21 \cdot 2^{\star \star}$ & 2.6 \\
\hline Body fat (\%) & 133 & $27 \cdot 8$ & 5.4 & $28 \cdot 8$ & $5 \cdot 0$ & $26 \cdot 4^{\star}$ & $5 \cdot 7$ \\
\hline Exercise (min/week) & 133 & 114 & 95 & 131 & 89.5 & $90 \cdot 0^{*}$ & $97 \cdot 9$ \\
\hline BMR (kJ/d per kg) & 133 & 101 & $9 \cdot 2$ & 99 & $8 \cdot 3$ & $104 \cdot 6^{\star \star}$ & $9 \cdot 4$ \\
\hline Length of menstrual cycle (d) & 128 & $28 \cdot 3$ & $2 \cdot 2$ & $28 \cdot 4$ & $1 \cdot 7$ & $28 \cdot 1$ & $2 \cdot 8$ \\
\hline Total cholesterol (mmol/l) & 131 & 4.6 & 0.8 & 4.5 & $0 \cdot 8$ & $4 \cdot 7$ & 0.8 \\
\hline TAG $(\mathrm{mmol} / \mathrm{l}) \dagger$ & 131 & $1 \cdot 1$ & $1 \cdot 7$ & 1.0 & $1 \cdot 7$ & $1 \cdot 2^{*}$ & 1.6 \\
\hline Daily energy intake (kJ) & 133 & $7867 \cdot 0$ & $1858 \cdot 9$ & $7846 \cdot 0$ & $1825 \cdot 4$ & $7896 \cdot 3$ & $1884 \cdot 0$ \\
\hline Energy from fat $(\%)$ & 133 & $18 \cdot 7$ & $3 \cdot 7$ & $18 \cdot 3$ & 3.4 & $19 \cdot 2$ & $4 \cdot 2$ \\
\hline Energy from PUFA (\%) & 133 & 3.6 & $1 \cdot 1$ & 3.6 & $1 \cdot 1$ & 3.6 & $1 \cdot 2$ \\
\hline Energy from MUFA (\%) & 133 & $7 \cdot 1$ & 1.6 & 6.9 & 1.4 & $7 \cdot 2$ & $1 \cdot 8$ \\
\hline Energy from SFA (\%) & 133 & $8 \cdot 0$ & $2 \cdot 2$ & 7.9 & $2 \cdot 0$ & $8 \cdot 4$ & $2 \cdot 5$ \\
\hline Energy from protein (\%) & 133 & 18.9 & $5 \cdot 6$ & $19 \cdot 1$ & $5 \cdot 1$ & $18 \cdot 5$ & $6 \cdot 2$ \\
\hline Energy from carbohydrates (\%) & 133 & $62 \cdot 5$ & $6 \cdot 2$ & $62 \cdot 6$ & $6 \cdot 0$ & $62 \cdot 3$ & $6 \cdot 5$ \\
\hline Alcohol (units/d) & 133 & $1 \cdot 8$ & 1.9 & $2 \cdot 0$ & 1.9 & 1.4 & $2 \cdot 0$ \\
\hline Restraint scores (Dutch Eating Behaviour Questionnaire) & 133 & $20 \cdot 6$ & $7 \cdot 6$ & $24 \cdot 9$ & $6 \cdot 4$ & $14 \cdot 5^{\star \star}$ & $4 \cdot 4$ \\
\hline
\end{tabular}

Mean value was significantly different from that for watchers: ${ }^{\star} P<0.05$, ${ }^{\star \star} P<0.0001$ (one-way ANOVA).

† Geometric mean. 


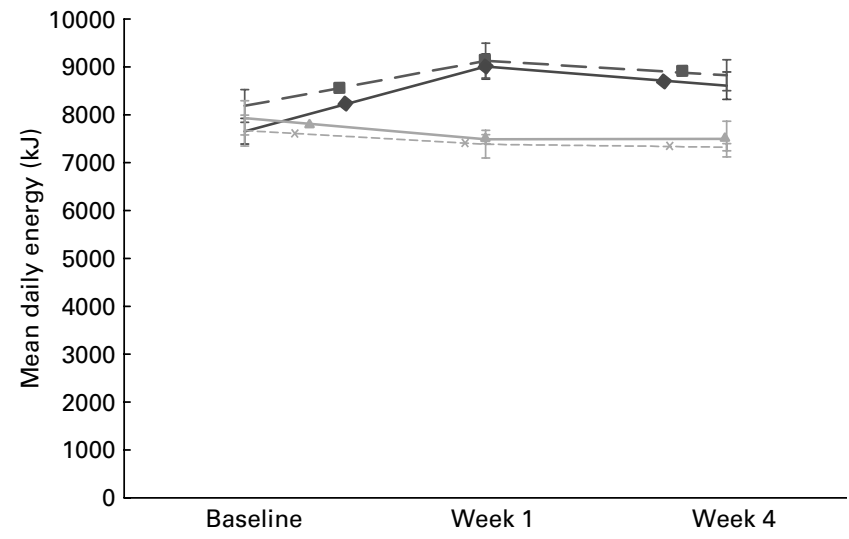

Fig. 1. Effects of sucrose or aspartame drink supplementation on energy intake over 4 weeks. Subjects expected drinks to contain sucrose, and the drinks contained sucrose (- $($ ) subjects expected the drinks to contain aspartame, and the drinks contained sucrose ( $\left.-{ }_{-} \cdot\right)$; subjects expected the drinks to contain sucrose, and the drinks contained aspartame ( - ); subjects expected the drinks to contain aspartame, and the drinks contained aspartame $(--\cdot)$. Values are means, with standard deviations represented by vertical bars.

Table 4 shows the main data at baseline and at week 1 and 4 of supplementation. Because there were no effects of restraint status or expectancy, data are broken down only by supplement.

\section{Body weight}

The mean body weight of the 133 women at baseline was 61.35 (SD 8.37) $\mathrm{kg}$. There was a marginal effect of drink on body weight $(F(10.20,1.86)=4.509 ; P<0.05)$, with more women who received the sucrose drink gaining some weight during the study and more women receiving aspartame losing weight. Fig. 3 plots weight gain against baseline BMI. It can be seen that most subjects gained or lost less than $2 \mathrm{~kg}$ during the study.

\section{Subjective state}

Across the 5 weeks, mood scores varied significantly as a function of time of day. In general linear modelling analyses mood also tended to change across the 5 weeks, but did not vary as a function of the experimental conditions. Fig. 4 shows mean rated tiredness (Z-corrected) across time of day and across the weeks. Tiredness is shown because the largest effect was found on this mood rating item. It can be seen that there is a marked variation in tiredness by time of day, with women being more tired at 18.00 and 20.00 hours than during the day. A trend for women to rate themselves less tired or more energetic across the study can be seen by comparing a given time of day across each week. There were similar trends (not shown) across the study for women to rate their mood less positively as the weeks progressed (less happy). More angry, anxious, ill, aroused, disgusted and restless; these were also modulated by circadian effects.

More detailed analysis revealed that there were significant effects of the expectancy manipulation on rated hunger during the baseline week, that is, before any test drinks were given. In general linear modelling using time of day and day of week as repeated measures across the baseline week, with drink and expectancy as independent factors, there were significant effects of time of day $(F=27.96$ $(3,83 \mathrm{df}) ; \quad P<0.001)$, a day $\times$ time interaction $(F=2.45$ $(18,68 \mathrm{df}) ; P<0.005)$ and a day $\times$ drink $\times$ expectancy interaction $(F=5.07(3,83 \mathrm{df}) ; P<0.005)$. In the first and final week of the intervention there were no equivalent effects, but only effects involving day and time of day. Fig. 4 shows rated hunger across the baseline $7 \mathrm{~d}$. It can be seen that those anticipating receiving diet soft drinks the following week tended to vary less across time of day in their hunger ratings than those anticipating sugary soft drinks. The latter groups tended to rate themselves hungrier at 11.00 and 18.00 hours, generally before eating main meals (Fig. 5).

\section{Discussion}

The present study set out to establish the effects of adding sucrose to the diet over 4 weeks, compared with artificially sweetened control drinks. In short, sugar satiated, leading to reduced energy intake and reduced intake of carbohydrate, fat and protein, without mood or hunger effects. However, satiety was imperfect.

Normal-weight women compensated for the added sucrose by reducing energy intake elsewhere, particularly choosing less

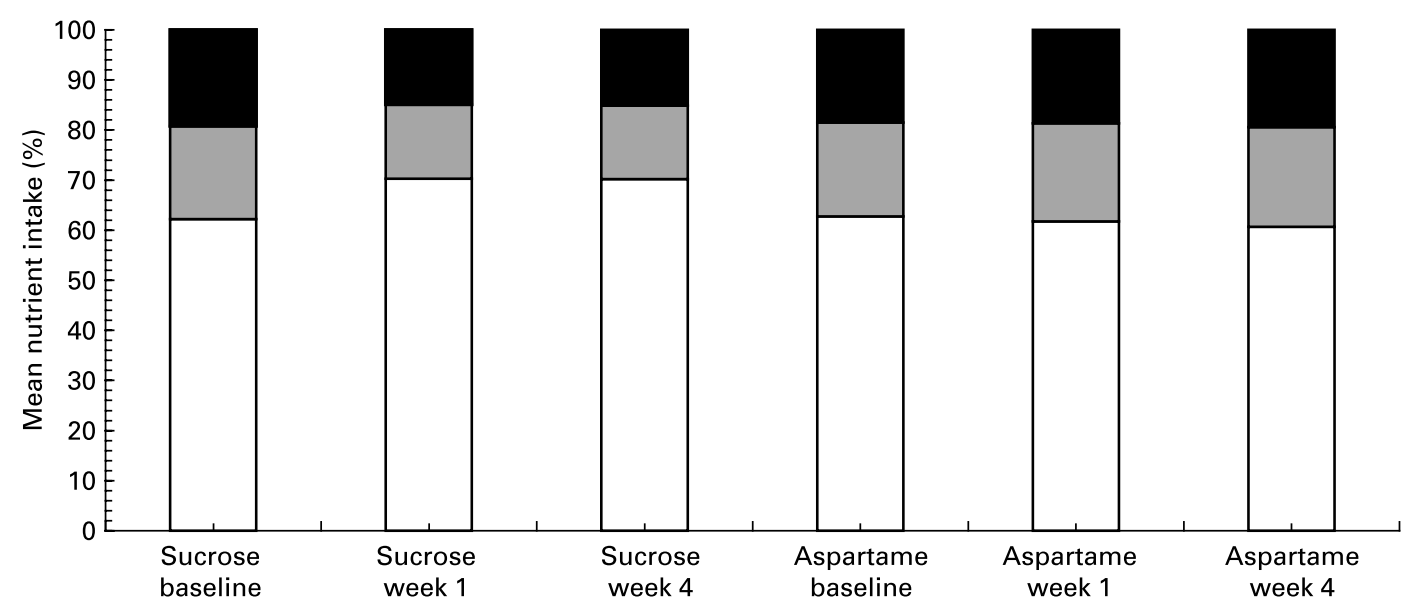

Fig. 2. Effects of sucrose or aspartame drink supplementation on proportional nutrient intake over 4 weeks. ( $\square$ ), Protein; ( $\square$ ), fat; ( $\square$ ), carbohydrate. 


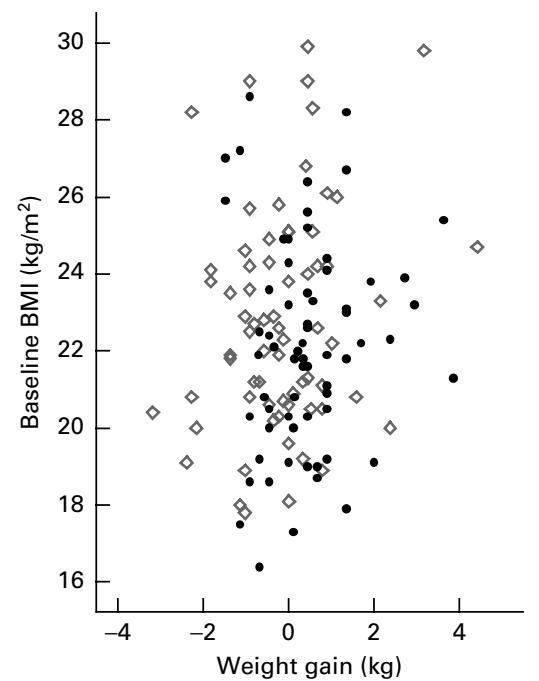

Fig. 3. Weight gain after 4 weeks of supplementation with sucrose- $(\diamond)$ or aspartame-containing $(\bullet)$ drinks.

carbohydrate in their free diets, but also reducing fat and protein intake. Fat intake reduced significantly, by some $6 \mathrm{~g}$ perd, but with large individual differences. However, there was not complete compensation for the added sucrose; women receiving it consumed about $800 \mathrm{~kJ}$ more energy per d, although the supplements contained $1800 \mathrm{~kJ}$. In terms of carbohydrate-specific compensation, women reduced their free carbohydrate intake by about half the quantity in the fixed supplement (approximately $50 \mathrm{~g}$ of $105 \mathrm{~g}$ ). The incomplete compensation tended to lead to some weight gain, although this trend was not significant; there were large individual differences in weight fluctuation over the study and for most women the weight gained (or lost) over the 4 weeks was less than $2 \mathrm{~kg}$.

The study systematically varied level of dietary restraint amongst normal-weight women, but this did not affect the outcomes. While there were significant differences of the expected kind between women who watched what they ate and those who did not, both groups tended to eat low-fat diets with approximately $19 \%$ of energy from fat (Astrup et al. 2000). This applied both to women with higher restraint scores and those with lower restraint scores, which suggests that low-fat diets relative to population norms are not necessarily cognitively controlled in ways that are represented in questions about restraint. With hindsight, normal-weight 'non-watchers' may be mostly women who do not watch what they eat because they are habituated to a relatively healthy, low-fat diet. In contrast, non-watchers who eat a normative UK diet, higher in fat, may tend to become overweight and would have been excluded from the present study.

A consequent limitation of the findings is that they apply only to women of normal weight eating low-fat diets. Overweight or obese women, men and individuals currently eating higher-fat diets might have responded differently. In some studies, overweight individuals have gained more weight than in the present study (Ludwig et al. 2001; Raben et al. 2002). However, a number of studies have found that sucrose intake leads to reductions in body weight (Gibson, 1993; Bolton-Smith \& Woodward, 1994; Raben et al. 1997; Saris et al. 2000; Astrup et al. 2000). Further research is 


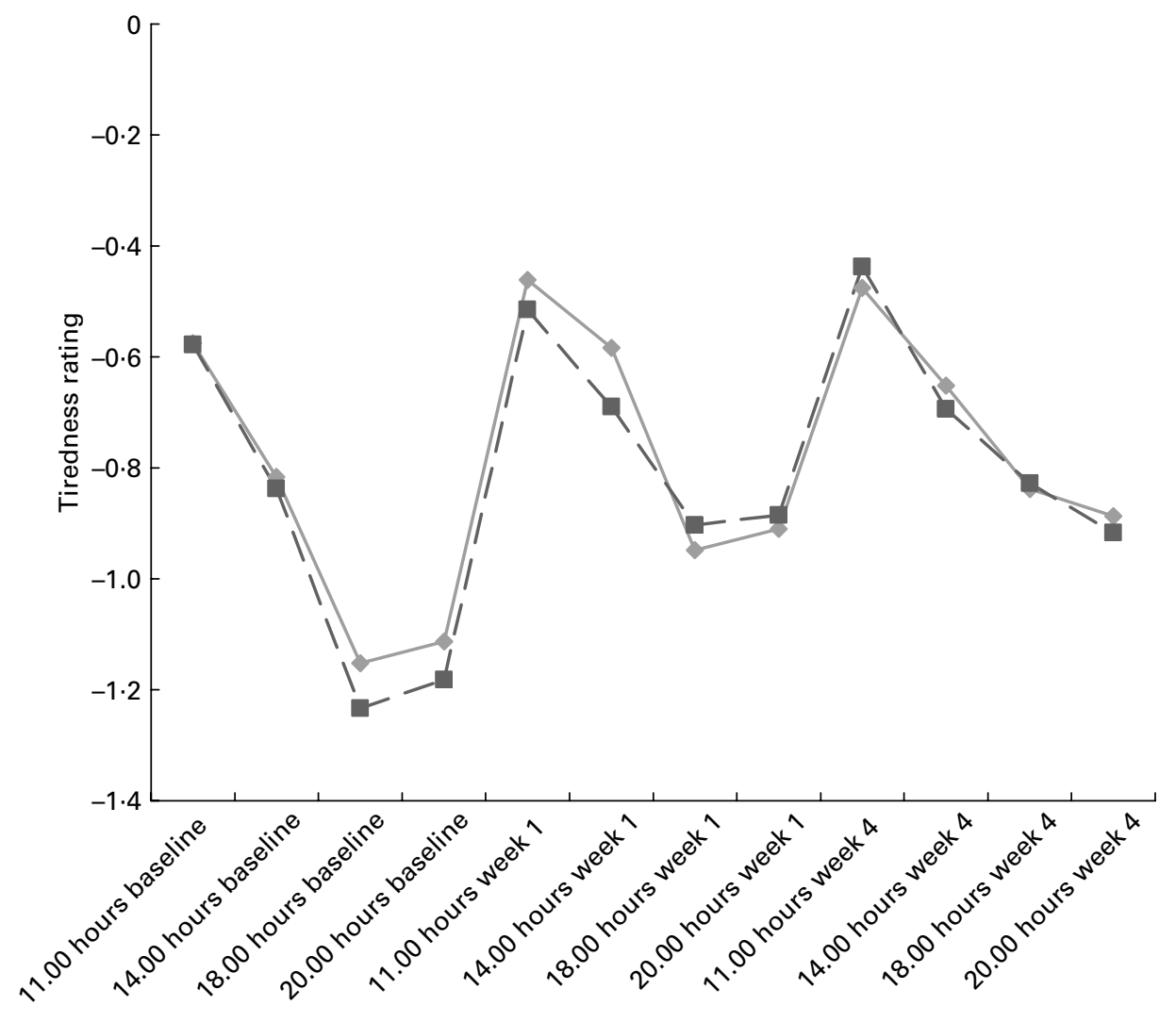

Fig. 4. Effects of sucrose (--) or aspartame (-ח-) drink supplementation on Z-corrected rated tiredness.

required to understand these variations, but respondents' diet before intervention and the magnitude of their weekly weight fluctuations may both be important. Furthermore, compensation may be poorer when subjects are not blind to the dietary manipulation, or when supplementation involves increased sweetness in the diet (Appleton et al. 2004).

Because the study only included normal-weight women eating low-fat diets, it cannot definitively answer the question of whether adding sucrose to the diet is an effective way of helping to reduce population fat intake. Participants did not need to reduce their fat intake, they reduced fat less than they compensated for added carbohydrate by reducing carbohydrate intake elsewhere, and the modest, non-significant, weight gain observed was not of clinical concern. The study needs to be replicated in overweight individuals who need to reduce fat intake and lose weight.

Another limitation of the study is that the mean daily increase in energy intake $(<1000 \mathrm{~kJ})$ was within the likely margin of reporting error in unweighed, free-living food diaries (de Castro, 1994). This makes the finding of partial compensation equivocal to interpret. Ideally, the findings need to be replicated with more accurate dietary recording, but this would be a challenge over 5 weeks.

Varying expectancies by labelling the drinks as being sugar or diet drinks and informing subjects what they were to receive in a counter-balanced design had no effect on the main study outcomes, showing that the physiological mechanisms underlying compensation were more important than psychological factors over 4 weeks. Expectancies did influence mood ratings but only during the baseline week when women anticipating diet drinks varied their hunger ratings less across the day. This shows that the procedure was sufficiently sensitive to detect mood changes and implies that the absence of mood effects of sucrose supplementation was unlikely to be a type II error. Mood also tended to change across the 4 weeks of the study, probably due to test fatigue. In protracted testing procedures participants may begin to respond more negatively purely because they dislike the procedure. Modelling mood effects after ingestion is complex (R Hammersley and M Reid, unpublished results).

It can be concluded that under controlled conditions psychological factors are not important determinants of the effects of carbohydrate on diet or mood, despite a popular literature promoting such effects (Reid \& Hammersley, 2001). When participants are accurately aware of what they are receiving, it is conceivable that popular beliefs could influence expectancies and lead to alterations in mood or diet. A working hypothesis, not rejected by these data, is that psychological influences such as expectancy effects are neither as consistent nor as persistent as physiological effects and hence more likely to be found in the short term (Reid et al. 2005a). This is consistent with previous findings on manipulating alcohol expectancies (Hammersley et al. 1998). Even if expectancy effects are inconsistent and do not persist over a period of weeks, they may inadvertently affect experimental results, particularly in non-blind, or repeated-measures, short-term designs (Bunting, 2001). The expected outcomes of eating do influence subsequent food choices (Reid et al. 2005a). 


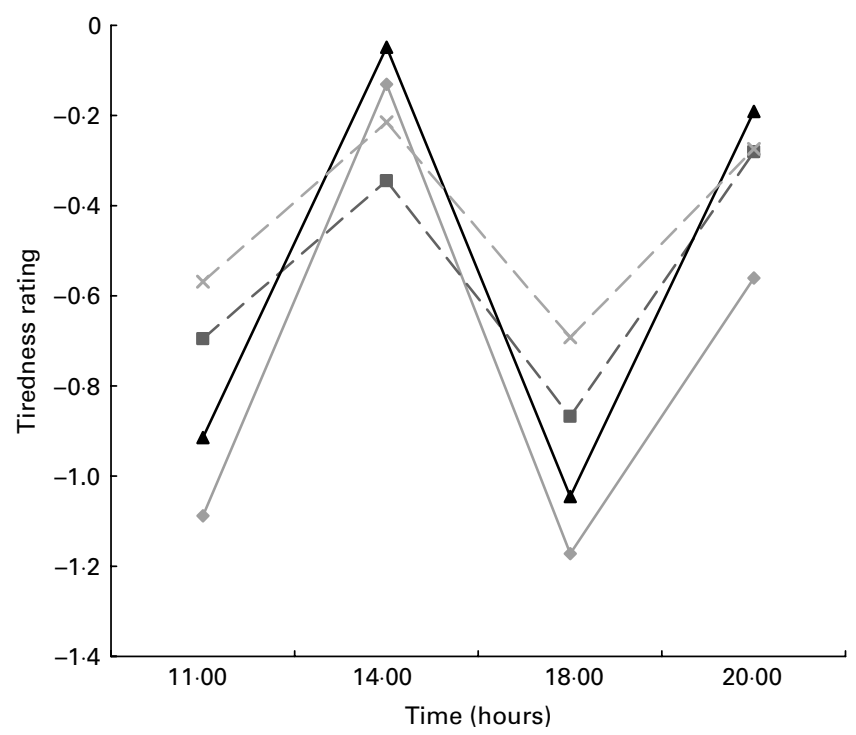

Fig. 5. Effects of anticipating sucrose or aspartame on Z-corrected rated hunger over the baseline week. Subjects expected drinks to contain sucrose, and the drinks contained sucrose (- - ); subjects expected the drinks to contain aspartame, and the drinks contained sucrose (- -$)$; subjects expected the drinks to contain sucrose, and the drinks contained aspartame $(-\mathbf{\Lambda}-)$; subjects expected the drinks to contain aspartame, and the drinks contained aspartame $(-\times-)$.

Implications of these findings are as follows. First, normalweight women compensate for added sucrose in the diet by reducing their free intake, particularly of carbohydrate. There was no evidence of women failing to compensate, or eating additional sweet or carbohydrate food, or experiencing adverse psychological effects. Second, it remains to be established whether overweight individuals would respond similarly and meantime it is premature to recommend adding sucrose-containing drinks to the diet to provide an energydense satiating alternative to fat. Third, there was evidence of nutrient-specific compensation for sucrose over 4 weeks, although this was not fully accurate. The mechanisms for nutrient-specific compensation remain to be established although these results support the findings that human subjects have a better appetite reduction response to carbohydrates than to fat (Rolls, 1986). Fourth, psychological expectancies did not influence mood or food choice over a period of weeks. The findings suggest that compensation over this time scale is physiologically rather than cognitively determined.

\section{Conclusions}

Overall, there was no evidence that sucrose was a unique or problematic substance. It is harder to compensate for energy-dense foods in general (Levitsky, 2005) and in the present study there was no evidence of adverse effects on mood, hunger or increased carbohydrate intake. However, compensation was only partial for added sucrose with only modest reductions in fat intake of about $6 \mathrm{~g}$ perd, so were sucrose to be added to the diet, with the aim of reducing fat intake, some weight gain might result in normal-weight individuals. Alternatively, compensation might continue to improve beyond 4 weeks with no eventual significant weight gain. A problem is that the current participants did not need to reduce fat intake. The impact of adding sucrose to the diets of overweight individuals and those eating higher-fat diets remains to be ascertained.

\section{Acknowledgements}

This research was conducted at the University of Essex (Colchester, Essex, UK), while the first, second and fourth authors were employed there. We are grateful to the Biotechnology and Biological Sciences Research Council (grant no. D12497) for financial support. We thank the Department of Biological Sciences at the University of Essex for taking the blood samples and Essex Rivers Hospital Trust (Colchester, Essex, UK) for analysis of the blood samples. M. R. and R. H. had the initial idea for the study, were responsible for obtaining funding and manuscript writing. R. H. was also responsible for data interpretation and statistical expertise. A. J. H. contributed to the design of the study, provided statistical expertise, and critically reviewed the manuscript for intellectual content. P. S. was responsible for overseeing subject recruitment, data collection, coding and data analysis. There were no conflicts of interest.

\section{References}

Allain CC, Poon LS, Chan CSG, Richmond W \& Fu PC (1974) Enzymatic determination of total cholesterol. Clin Chem 20, 470-475.

Appleton KM, Rogers PJ \& Blundell JE (2004) Effects of a sweet and a nonsweet lunch on short-term appetite: differences in female high and low consumers of sweet/low-energy beverages. J Hum Nutr Diet 17, 425-434.

Astrup A (2005) The satiating power of protein - a key to obesity prevention? Am J Clin Nutr 82, 1-2.

Astrup A, Grunwald GK, Melanson EL, Saris WH \& Hill JO (2000) The role of low-fat diets in body weight control: a meta-analysis of ad libitum dietary intervention studies. Int $J$ Obes Relat Metab Disord 24, 1545-1552.

Astrup A \& Raben A (1992) Obesity: an inherited metabolic deficiency in the control of macronutrient balance? Eur J Clin Nutr 46, 611-620.

Benton D (2002) Carbohydrate ingestion, blood glucose and mood. Neurosci Biobehav Rev 26, 293-308.

Blundell JE \& Burley VJ (1990) Evaluation of the satiating power of dietary fat in man. In Progress in Obesity Research [Y Oomura, 
S Atrui, S Inoue, T Shimazu editors], pp. 435-437. London: John Libby.

Blundell JE, Green S \& Burley VJ (1994) Carbohydrates and human appetite. Am J Clin Nutr 59, Suppl., 728S-734S.

Bolton-Smith C \& Woodward M (1994) Dietrary composition and fat to sugar ratios in relation to obesity. Int J Obes Relat Metab Disord 18, 820-828.

Brinkworth GD, Noakes M, Keogh JB, Luscombe ND, Wittert GA \& Clifton PM (2004) Long-term effects of a high-protein, low-carbohydrate diet on weight control and cardiovascular risk markers in obese hyperinsulinemic subjects. Int J Obes 28, 661-670.

British Nutrition Foundation (1999) Obesity: The Report of the British Nutrition Foundation Task Force. London: Blackwell Science.

Bucolo G \& David H (1973) Quantitative determination of serum triglycerides by the use of enzymes. Clin Chem 19, 476-482.

Bunting J () (2001) The role of expectancies in consumer food choice. PhD Thesis, Glasgow Caledonian University, Glasgow.

Byrnes A, Edwards CM, Ghatei MA, Dornhorst A, Morgan LM, Bloom SR \& Frost GS (2003) A randomised four-intervention crossover study investigating the effect of carbohydrates on daytime profiles of insulin, glucose, non-esterified fatty acids and triacylglycerols in middle-aged men. Br J Nutr 89, 207-218.

de Castro JM (1987) Macronutrient relationships with meal patterns and mood in the spontaneous feeding behaviour of humans. Physiol Behav 39, 561-569.

de Castro JM (1994) Methodology, correlational analysis, and interpretation of diet diary records of the food and fluid intake of free-living humans. Appetite 23, 179-192.

Department of Health (2002) Health Survey for England, Adults 1993-2002, Table 6. Excel spreadsheet. Accessed 2 October 2006. http://www.dh.gov.uk/PublicationsAndStatistics/PublishedSurvey/ HealthSurveyForEngland/HealthSurveyResults/HealthSurvey ResultsArticle/fs/en?CONTENT_ID=4001334\&chk=RgQBk4.

de Graaf C, Blom WAM, Smeets PAM, Stafleu A \& Hendriks HFJ (2004) Biomarkers and satiation and satiety. Am J Clin Nutr 79, 946-961.

Geiselman PT \& Novin D (1982) Sugar infusion can enhance feeding. Science 218, 490-491.

Gibson SA (1993) Consumption and sources of sugars in the diet of British school children: are high-sugar diets nutritionally inferior? J Hum Nutr Diet 6, 355-371.

Goran MI (2001) Metabolic precursors and effects of obesity in children: a decade of progress, 1990-1999. Am J Clin Nutr 73, 158-171.

Goris AHC, Meijer EP \& Westerterp KR (2001) Repeated measurement of habitual food intake increases underreporting and induces selective underreporting. Br J Nutr 85, 629-634.

Hammersley R, Finnigan F \& Millar K (1998) Verbal expectancies and performance after alcohol. Addict Behav 23, 489-496.

Hill AJ \& Blundell JE (1986) Macronutrients and satiety: the effects of a high protein or high carbohydrate meal on subjective motivation to eat and food preferences. Nutr Behav 3, 133-144.

Hill JO, Melanson EL \& Wyatt HT (2000) Dietary fat intake and regulation of energy balance: implications for obesity. $J$ Nutr 130, 284S-288S.

Levitsky DA (2005) The non-regulation of food intake in humans: hope for reversing the epidemic of obesity. Physiol Behav 86, $623-632$.

Lieberman HR, Wurtman J \& Chew B (1986) Changes in mood after carbohydrate consumption among obese individuals. Am J Clin Nutr 45, 772-778.

Ludwig DS, Peterson KE \& Gortmaker SL (2001) Relation between consumption of sugar-sweetened drinks and childhood obesity: a prospective, observational analysis. Lancet 357, 505-508.

Ministry of Agriculture, Fisheries and Food (1991) National Food Survey Annual Reports on Household Food Consumption and Expenditure. London: H.M. Stationery Office.
Nelson M, Atkinson M \& Meyer J (1997) A Photographic Atlas of Food Portion Sizes. London: MAFF Publications.

Nichter M, Ritenbaugh C, Nichter M, Vuckovic N \& Aickin M (1995) Dieting and "watching" behaviours among adolescent females: report of a multimethod study. J Adolesc Health 17, $153-162$.

Pivonka EEA \& Grunewald KK (1990) Aspartame or sugar sweetened beverages effects on mood in young women. $J$ Am Diet Assoc Res 90, 250-252.

Poppitt SD, Keogh GF, Prentice AM, Williams DE, Sonnemans HM, Valk EE, Robinson E \& Wareham NJ (2002) Long-term effects of ad libitum low-fat, high-carbohydrate diets on body weight and serum lipids in overweight subjects with metabolic syndrome. Am J Clin Nutr 75, 11-20.

Poulton EC (1989) Bias in Quantifying Judgements. London: Erlbaum.

Prentice A \& Jebb SA (1995) Obesity in Britain: gluttony or sloth? Br Med J 311, 437-439.

Raben A, Macdonald I \& Astrup A (1997) Replacement of dietary fat by sucrose or starch: effects on $14 \mathrm{~d}$ ad libitum energy intake, energy expenditure and body weight in formerly obese and never-obese subjects. $J$ Obes Relat Metab Disord 21, 846-859.

Raben A, Vasilaras TH, Moller AC \& Astrup A (2002) Sucrose compared with artificial sweeteners: different effects on ad libitum food intake and body weight after 10 weeks of supplementation in overweight subjects. Am J Clin Nutr 76, 721-729.

Reid M, Bunting J \& Hammersley R (2005a) The relationship between the Food Expectancy Questionnaire (FEQ) and selfreported eating behaviour. Appetite 45, 127-136.

Reid M \& Hammersley R (1998) The effect of blind substitution of aspartame sweetened for sugar-sweetened soft drinks on appetite and mood. Br Food J 100, 254-259.

Reid M \& Hammersley RH (1999) The effects of carbohydrate consumption on subjective mood state - a review of methodology. Nutr Res Rev 12, 3-23.

Reid M \& Hammersley RH (2001) Dependence-like features of carbohydrates. In Food Cravings and Addiction, pp. 477-494 [MM Hetherington, editor]. Leatherhead, UK: Leatherhead Food Research Association.

Reid M, Hammersley R \& Rance J (2005b) Restraint, dieting and watching what you eat among female students. Nutr Bull 30, $120-125$.

Reid M \& Hetherington M (1997) The effects of carbohydrates and protein on satiety; a review of methodology. Neurosci Biobehav Rev 21, 295-308.

Roese NJ \& Jamieson DW (1993) 20 Years of bogus pipeline research - a critical review and meta-analysis. Psychol Bull 114, $363-375$.

Rolls B (1986) Sensory specific satiety. Nutr Rev 44, 93-101.

Saris WHM (2003) Sugars, energy metabolism, and body weight control. Am J Clin Nutr 78, Suppl., 850S-857S.

Saris WHM, Astrup A, Prentice AM, et al. (2000) Randomized controlled trial of changes in dietary carbohydrate/fat ratio and simple vs complex carbohydrates on body weight and blood lipids: the CARMEN study. Int J Obes Relat Metab Disord 24, 1310-1318.

Satia JA, Keku T, Galanko JA, Martin C, Doctolero RT, Tajima A, Sandler RS \& Carethers JM (2005) Diet, lifestyle, and genomic instability in the North Carolina colon cancer study. Cancer Epidemiol Biomarkers Prev 14, 429-436.

Skidmore PM \& Yarnell JW (2004) The obesity epidemic: prospects for prevention. QJM 97, 817-825.

Spitzer L \& Rodin J (1987) Effects of fructose and glucose preloads on subsequent food intake. Appetite 8, 135-145.

Surwit RS, Feinglos MN, McCaskill CC, Clay SL, Babyak MA, Brownlow BS, Plaisted CS \& Lin PH (1997) Metabolic and 
behavioural effects of a high-sucrose diet during weight loss. Am J Clin Nutr 65, 908-915.

Teff KL, Young SN \& Blundell JE (1989) The effect of protein or carbohydrate breakfasts on subsequent plasma amino acid levels, satiety and nutrient selection in normal males. Pharmacol Biochem Behav 34, 829-837.

Thayer RE (1978) Factor analytic and reliability studies on the Activation-Deactivation Adjective Check List. Psychol Rep 42, 747-756.

Thayer RE (1987) Energy, tiredness, and tension effects of a sugar snack versus moderate exercise. J Pers Soc Psychol 52, $119-125$.
Toornvliet AC, Pijl H, Tuinenburg J, Wever BME \& Pieters MS (1997) Psychological and metabolic responses of carbohydrate craving obese patients to carbohydrate, fat and protein-rich meals. Int $J$ Obes 21, 860-864.

Tordoff MG \& Alleva M (1990) Effect of drinking soda sweetened with aspartame or high-fructose corn syrup on food intake and body weight. Am J Clin Nutr 51, 963-969.

van Strien T, Frijters JER, Bergers GPA \& Defares PB (1986) The Dutch Eating Behaviour Questionnaire (DEBQ) for assessment of restrained, emotional, and external eating behavior. Int $J$ Eat Disord 5, 295-315. 